\title{
PENGARUH KONSUMSI MAKANAN LAUT TERHADAP KEJADIAN HIPERTENSI DI DESA MALALAYANG DUA
}

\author{
${ }^{1}$ Stephen Masengi \\ ${ }^{2}$ Stella Palar \\ ${ }^{2}$ Linda Rotty
}

\author{
${ }^{1}$ Kandidat Skripsi Fakultas Kedokteran Universitas Sam Ratulangi Manado \\ ${ }^{2}$ Bagian Ilmu Penyakit Dalam Fakultas Kedokteran Universitas Sam Ratulangi Manado \\ Email: stephen_masengi@yahoo.com
}

\begin{abstract}
Hypertension is one of the important preventable causes of morbidity and mortality in developed and developing countries. $\omega-3$ and $\omega-6$ poly-unsaturated fatty acids (PUFA), are essential for the body and obtained from food. Fish oil is useful to change $\omega-3$ to $\omega-6$ in lowering blood pressure (BP), the risk of myocardial infarction and useful in life-threatening situation. The purpose of this study was to obtain the prevalence of hypertension in Malalayang Dua village and the relationship between seafood consumption with the prevalence of hypertension in that area. The research sample was urban communities of Malalayang Dua village Lingkungan III over the age of 18 years. We use category of hypertension and non-hypertension by the U.S. Joint National Committee (JNC) 7, and seafood consumption divided by less, moderate and much. Completion of the questionnaire by the study subjects, BP measurement using an aneroid sphygmomanometer and analysis of data to determine the relationship between the consumption of seafood with BP, using linear regression analysis. Conclusion: The prevalence of hypertension in this area is $6.3 \%$, and there is a significant relationship between seafood consumption and hypertension ( $p=0.001)$.

Keywords : hypertension, seafood consumption
\end{abstract}

\begin{abstract}
Abstrak: Hipertensi merupakan salah satu penyebab penting dari morbiditas dan mortalities yang dapat dicegah di negara maju dan berkembang. Asam lemak, yaitu poly-unsaturated fatty acid (PUFA) $\omega-3$ dan $\omega$-6,penting untuk tubuh dan didapatkan dari makanan. Minyak ikan berguna untuk mengubah $\omega-3$ menjadi $\omega-6$ dalam menurunkan tekanan darah (TD) dan berbagai risiko terjadinya miokard infark pada situasi yang berbahaya dan mengancam jiwa. Tujuan penelitian ini adalah untuk memperoleh angka kejadian hipertensi di masyarakat kelurahan Malalayang Dua dan hubungan antara konsumsi makanan laut dengan angka kejadian hipertensi tersebut. Sampel penelitian adalah masyarakat kelurahan Malalayang Dua Lingkungan III yang berusia lebih dari 18 tahun. Kriteria tekanan darah pada penelitian ini berdasarkan US Joint National Committee (JNC) 7, dan konsumsi makanan laut dibagi atas kurang, sedang dan banyak. Pengisian kuesioner oleh subyek penelitian, pengukuran TD menggunakan sfigmomanometer aneroid dan analisa data untuk mengetahui hubungan antara konsumsi makanan laut dengan TD, menggunakan analisa regresi linear. Kesimpulan: Angka hipertensi di daerah ini yaitu, 6,3\%, dan terdapat hubungan yang signifikan antara konsumsi makanan laut dengan kejadian hipertensi $(\mathrm{p}=0.001)$.
\end{abstract}

Kata Kunci : hipertensi, konsumsi makanan laut

Sampai saat ini, hipertensi masih tetap menjadi masalah karena beberapa hal, antara lain meningkatnya prevalensi hipertensi, masih banyaknya pasien hipertensi yang belum mendapat pengobatan maupun yang sudah diobati 
tetapi tekanan darahnya belum mencapai target, serta adanya penyakit penyerta dan komplikasi yang dapat meningkatkan morbiditas dan mortalitas. ${ }^{1}$ Data epidemiologi terbaru juga telah memperlihatkan kecenderungan di mana kebanyakan orangorang dengan TD yang tinggi-normal akan menjadi hipertensi seiring dengan bertambahnya usia. $^{2}$ Orang-orang dengan TD tinggi-normal ini yang kemudian digolongkan dalam pre-hipertensi menurut pengklasifikasian menurut JNC $7 .^{3}$ Untuk orang-orang yang tergolong dalam prehipertensi, British Hypertension Society (BHS) menyadari perlunya modifikasi dari gaya hidup untuk mencegah berkembangnya menjadi hipertensi. ${ }^{4}$

Tubuh manusia dapat memproduksi beberapa asam lemak, namun ada juga asam lemak yang tidak dapat diproduksi. Asam lemak ini, yaitu PUFA $\omega-3$ dan $\omega$ 6,penting untuk tubuh dan didapatkan dari makanan. Akhir-akhir ini, pada kebanyakan makanan olahan hanya terdapat asam lemak $\omega-6$, oleh karenanya rasio $\omega-3$ dibandingkan $\omega-6$ sangatlah rendah. Minyak ikan berguna untuk mengubah secara cepat $\omega-3$ menjadi $\omega-6$ dalam menurunkan TD dan berbagai risiko terjadinya miokard infark pada situasi yang berbahaya dan mengancam jiwa. Untuk mencegah kekurangan asam lemak esensial, para ahli merekomendasikan untuk mengonsumsi setidaknya 2.4 persen total lemak yang dikonsumsi adalah $\omega-6$ dan 0.5 hingga 1 persen total lemak terdiri dari $\omega-3$. Mengkonsumsi satu hingga empat porsi (sekitar 100 gram per sajian) ikan seminggu baik untuk kesehatan. Jumlah ini dapat dibilang aman, mengingat jumlah logam berat (seperti merkuri) dan kontaminan lainnya yang terdapat di laut, kecuali ikan tersebut diambil dari daerah tanpa kontrol polusi. Beberapa penelitian mempelajari tentang suplementasi minyak ikan menunjukkan bahwa pada pasien hipertensi, terlihat penurunan signifikan pada TD, namun studi lain menunjukkan efek yang minimal terhadap penurunan TD. ${ }^{5}$

Masyarakat kelurahan Malalayang
Dua, yang sebagian besarnya menghuni pesisir pantai, tentunya tidak asing dengan konsumsi makanan laut. Apalagi dengan dibukanya rumah-rumah makan makanan laut yang relatif penuh tiap hari, dapat dilihat minat dan kesukaan warga terhadap makanan laut ini. Hipertensi sudah masuk dalam 10 penyakit umum di Puskesmas Bahu. Hal ini menunjukkan meningkatnya prevalensi hipertensi di masyarakat setempat. Sampai saat ini, belum ada studi yang meneliti hubungan secara langsung antara kejadian hipertensi dengan pola konsumsi masyarakat terhadap makanan laut di Manado, terlebih khusus di kelurahan Malalayang Dua.

\section{METODE PENELITIAN}

Penelitian ini merupakan penelitian observasional analitik dengan cross sectional study (studi potong lintang). Penelitian ini dilaksanakan pada bulan November-Desember 2012 bertempat di kelurahan Malalayang Dua Lingkungan III Manado. Populasi penelitian adalah masyarakat kelurahan Malalayang Dua Lingkungan III. Sampel penelitian adalah masyarakat kelurahan Malalayang Dua Lingkungan III yang berusia 18 tahun. Digunakan metode consecutive sampling untuk pengambilan sampel. Jumlah sampel minimum yang harus diambil adalah sebanyak 92 orang, ${ }^{6}$ dan yang termasuk dalam kriteria eksklusi adalah orang-orang yang mengonsumsi garam sebanyak $>2,4$ gram, menderita/mempunyai riwayat hipertensi sekunder, riwayat penyakit ginjal, riwayat penyakit gagal jantung. Variabel penelitian ini adalah pola konsumsi makanan laut dengan tekanan darah, dimana pola konsumsi makanan laut merupakan variabel bebas dan tekanan darah merupakan variabel terikat.

Makanan laut, di dalamnya terdapat ikan bersirip dan makhluk akuatik lainnya seperti krustasea dan moluska, ${ }^{3}$ dapat digambarkan melalui kuesioner dan digolongkan dalam tingkatan kurang, sedang dan banyak, di mana konsumsi dinyatakan dalam kurang, sedang, dan 
banyak. Dalam penelitian ini, dikatakan konsumsi makanan laut kurang, bila konsumsi makanan laut per minggu kurang dari 100 gram, sedang bila konsumsi makanan laut per minggu sekitar 100-400 gram, dan banyak bila konsumsi makanan laut per minggu melebihi 400 gram. Nominal ini didapatkan dari perkalian antara rata-rata banyaknya makanan laut dalam sekali makan dan frekuensi konsumsi makanan laut seminggu. Oleh karena itu, yang termasuk dalam kategori kurang adalah sampel dengan rata-rata konsumsi makanan laut sekali makan kurang dari 100 gram dan frekuensi konsumsi makanan laut sekitar 1-4 kali seminggu; yang termasuk dalam kategori sedang adalah sampel dengan rata-rata konsumsi makanan laut sekali makan lebih dari 100 gram dan frekuensi konsumsi makanan laut dalam seminggu sekitar 1-4 kali atau mempunyai rata-rata konsumsi makanan laut sekali makan kurang dari 100 gram, namun frekuensi konsumsi makanan laut dalam seminggu lebih dari empat kali; dan yang masuk dalam kategori banyak adalah sampel dengan rata-rata konsumsi makanan laut sekali makan lebih dari 100 gram dan frekuensi konsumsi makanan laut dalam seminggu lebih dari empat kali.

Tekanan darah adalah daya yang dihasilkan oleh darah terhadap setiap satuan luas dinding pembuluh, dinyatakan dalam millimeter air raksa, ${ }^{7}$ diukur melalui alat sfignomanometer aneroid dan digolongkan dalam kriteria non-hipertensi dan hipertensi. Sampel yang termasuk dalam kriteria non-hipertensi adalah sampel yang bertekanan darah tergolong dalam tingkatan normal menurut JNC 7, yaitu tekanan darah sistolik kurang dari 120 $\mathrm{mmHg}$ dan diastolik kurang dari $80 \mathrm{mmHg}$, dan pre-hipertensi, yaitu tekanan darah sistolik berkisar 120-139 mmHg dan/atau tekanan darah diastolik 80-89 mmHg, sedangkan sampel yang termasuk dalam kriteria hipertensi adalah sampel dengan tekanan darah yang tergolong hipertensi stage 1 (tekanan darah sistolik berkisar 140-159 mmHg dan/atau tekanan darah diastolik 90-99 mmHg) dan hipertensi stage 2 (tekanan darah sistolik lebih dari atau sama dengan $160 \mathrm{mmHg}$ dan/atau tekanan darah diastolik lebih dari atau sama dengan $100 \mathrm{mmHg}$ ) berdasarkan JNC 7.

\section{HASIL PENELITIAN}

Setelah dilakukan pengambilan data primer pada masyarakat Malalayang Dua, tepatnya di lingkungan III sekitar terminal Malalayang, didapatkan sampel sebanyak 95 orang.

Tabel 1. Distribusi sampel menurut jenis kelamin, usia, dan status tekanan darah

\begin{tabular}{|c|c|c|c|}
\hline \multirow{2}{*}{ Jenis Kelamin } & \multirow{2}{*}{ Usia } & \multicolumn{2}{|c|}{ Tekanan Darah } \\
\hline & & Normotensi & Hipertensi \\
\hline \multirow[t]{6}{*}{ Laki-laki } & $18-25$ & 6 & 0 \\
\hline & $26-35$ & 4 & 0 \\
\hline & $36-45$ & 4 & 0 \\
\hline & $46-55$ & 1 & 1 \\
\hline & $56-65$ & 4 & 0 \\
\hline & Total & 19 & 1 \\
\hline \multirow[t]{6}{*}{ Perempuan } & $18-25$ & 17 & 0 \\
\hline & $26-35$ & 22 & 1 \\
\hline & $36-45$ & 20 & 2 \\
\hline & $46-55$ & 9 & 2 \\
\hline & $56-65$ & 2 & 0 \\
\hline & Total & 70 & 5 \\
\hline \multirow[t]{6}{*}{ Total } & $18-25$ & 23 & 0 \\
\hline & $26-35$ & 26 & 1 \\
\hline & $36-45$ & 24 & 2 \\
\hline & $46-55$ & 10 & 3 \\
\hline & $56-65$ & 6 & 0 \\
\hline & Total & 89 & 6 \\
\hline
\end{tabular}

Di bawah ini adalah diagram jenis makanan laut yang paling sering dikonsumsi warga, distribusi sampel berdasarkan frekuensi dan banyaknya makanan laut yang dikonsumsi dan distribusi sampel berdasarkan konsumsi makanan laut. 


\section{Jenis Makanan Laut yang Paling Sering Dikonsumsi}

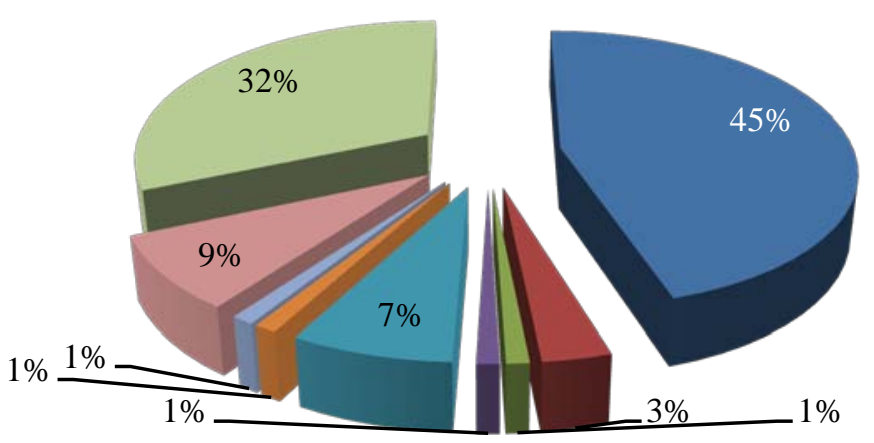

- Ikan cakalang (Katsuwonus pelamis)

- Ikan deho (Auxis thazard)

- Ikan goropa (Plectropomus leopardus)

- Ikan roa (Hemiramphus brasiliensis)

- Ikan malalugis (Decapterus sp.)

- Oci (Clupeidae)

- Tindarung (Xiphias gladius)

Tude (Decapterus russelli)

Ikan (non-spesifik)

Gambar 1. Diagram jenis makanan laut yang paling sering dikonsumsi

Tabel 2. Distribusi sampel berdasarkan frekuensi dan banyaknya makanan laut yang dikonsumsi

\begin{tabular}{|c|c|c|c|}
\hline \multirow{2}{*}{$\begin{array}{c}\text { Banyaknya } \\
\text { Makanan } \\
\text { Laut Sekali } \\
\text { Makan }\end{array}$} & \multirow{2}{*}{$\begin{array}{c}\text { Frekuensi } \\
\text { Konsumsi } \\
\text { dalam } \\
\text { Seminggu }\end{array}$} & \multicolumn{2}{|c|}{ Tekanan Darah } \\
\hline & & Normotensi & Hipertensi \\
\hline \multirow{3}{*}{$<100$ gram } & $\begin{array}{c}1-4 \text { kali } \\
\text { seminggu }\end{array}$ & 2 & 1 \\
\hline & $\begin{array}{c}>4 \text { kali } \\
\text { seminggu }\end{array}$ & 34 & 5 \\
\hline & Total & 36 & 6 \\
\hline \multirow{3}{*}{ > 100 gram } & $\begin{array}{c}\text { 1-4 kali } \\
\text { seminggu }\end{array}$ & 0 & 0 \\
\hline & $\begin{array}{c}>4 \text { kali } \\
\text { seminggu }\end{array}$ & 53 & 0 \\
\hline & Total & 53 & 0 \\
\hline \multirow{3}{*}{ Total } & $\begin{array}{c}1-4 \text { kali } \\
\text { seminggu }\end{array}$ & 2 & 1 \\
\hline & $\begin{array}{c}>4 \text { kali } \\
\text { seminggu }\end{array}$ & 87 & 5 \\
\hline & Total & 89 & 6 \\
\hline
\end{tabular}

Tabel 3. Distribusi sampel berdasarkan konsumsi makanan laut

\begin{tabular}{ccc}
\hline $\begin{array}{c}\text { Konsumsi makanan } \\
\text { laut }\end{array}$ & Jumlah & Persentase \\
\hline $\begin{array}{c}\text { Konsumsi Makanan Laut } \\
\text { Banyak }\end{array}$ & 53 & $55,8 \%$ \\
$\begin{array}{c}\text { Konsumsi Makanan Laut } \\
\text { Sedang }\end{array}$ & 39 & $41,1 \%$ \\
$\begin{array}{c}\text { Konsumsi Makanan Laut } \\
\text { Kurang }\end{array}$ & 3 & $3,2 \%$ \\
Total & 95 & $100 \%$ \\
\hline
\end{tabular}

Tabel 4. Distribusi sampel berdasarkan tekanan darah

\begin{tabular}{ccc}
\hline Hipertensi & Jumlah & Persentase \\
\hline Normotensi & 89 & $93,7 \%$ \\
Hipertensi & 6 & $6,3 \%$ \\
Total & 95 & $100 \%$ \\
\hline
\end{tabular}

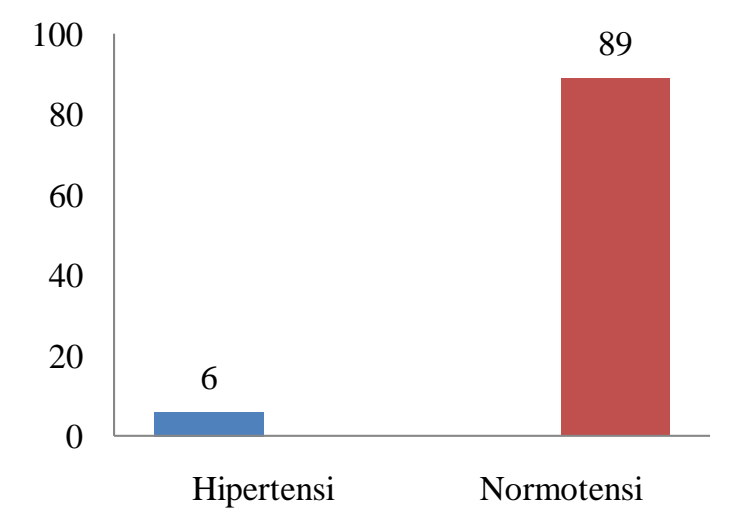

Gambar 2. Diagram prevalensi hipertensi

Sampel diuji berdasarkan hubungan antara hipertensi sebagai variabel terikat, dengan konsumsi makanan laut sebagai variabel bebas beserta faktor-faktor risiko penyebab hipertensi lainnya, seperti umur, jenis kelamin, konsumsi alkohol, merokok, riwayat DM, riwayat DM pada keluarga, riwayat dislipidemia, dan riwayat dislipidemia pada keluarga, kemudian dilakukan analisis regresi linear, dan didapatkan $p=0.001$. 


\section{PEMBAHASAN}

Dari distribusi data menurut usia, dapat dilihat bahwa kelompok usia terbanyak tergolong dalam usia 26-35 tahun, dan yang paling sedikit terdapat dalam usia 56-65 tahun. Belum ada penelitian yang mengatakan jumlah konsumsi makanan laut berkurang seiring dengan bertambahnya usia. Oleh karena itu, tidak ada batasan usia dalam penelitian ini. Berdasarkan jenis kelamin, jumlah sampel wanita sebanyak 75 orang (78,9\%). Peneliti mendatangi rumah-rumah warga pada waktu siang-sore, dan pada saat demikian paling banyak dijumpai wanita, sedangkan populasi pria sebagian besar sedang bekerja. Jenis makanan laut yang paling banyak dikonsumsi adalah ikan cakalang (Katsuwonus pelamis). Ikan ini terdapat kosmopolitan di daerah tropis, dekat dengan pesisir pantai dan air yang relatif hangat. Ikan ini cukup penting bagi perikanan karena termasuk dalam komoditi yang banyak diminati. Ikan cakalang yang disuplai warga masyarakat Malalayang Dua Lingkungan III berasal dari laut. Ikan ini memakan krustasea, sefalopoda, moluska dan ikan lain, dan bisa dibilang termasuk dalam rantai makanan dengan golongan yang cukup tinggi, oleh karena itu akumulasi metilmerkuri dalam ikan golongan ini relatif tinggi, dan risiko terjadinya penyakit minamata tergantung dari kadar merkuri lautan sekitar. ${ }^{8}$

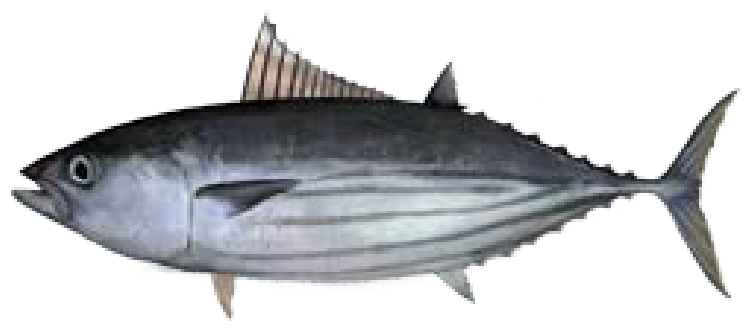

Gambar 3. Ikan cakalang (Katsuwonus pelamis), makanan laut yang paling banyak dikonsumsi masyarakat kelurahan Malalayang Dua
Sebanyak $8.4 \%$ populasi target mengatakan mereka sering memakan ikan tude (Decapterus russelli), tujuh orang mengatakan ikan malalugis (Decapterus sp.), tiga orang memakan ikan deho (Auxis thazard) sebanyak tiga orang (3,2 \%). Sisanya, masing-masing 1 orang sampel (1 \%) mengatakan bahwa ikan goropa (Plectropomus leopardus), ikan roa (Hemiramphus brasiliensis), ikan oci (Clupeidae), dan tindarung (Xiphias gladius) adalah makanan laut yang paling sering dimakan.

Didapatkan jumlah sampel dengan konsumsi makanan laut yang termasuk kurang sebanyak tiga orang (3,2 \%), termasuk dalam kategori sedang sebanyak 39 orang (41,1 \%), dan termasuk dalam kategori konsumsi makanan laut banyak sejumlah 53 orang (55,8 \%). Jumlah sebesar 53 orang yang mengonsumsi makanan laut dalam kategori banyak. Hal ini menunjukkan minat dan kebiasaan masyarakat dalam mengonsumsi makanan laut ini.

Didapatkan kejadian hipertensi pada masyarakat Malalayang Dua Lingkungan III sebesar 6,3 \%. Berbeda dengan yang dikemukakan oleh Appleby et al, ${ }^{9}$ yaitu bahwa prevalensi hipertensi untuk pemakan ikan adalah sebesar 9,3\% untuk pria, dan 9,7 \% untuk wanita. Dalam penelitian kali ini, didapatkan penurunan angka prevalensi hipertensi yang cukup bermakna. Hal ini dapat terjadi karena perbedaan lokasi penelitian dan jumlah sampel antara penelitian ini dengan penelitian yang dilakukan oleh Appleby et al.

Dari hasil analisis regresi linear, didapatkan nilai $p=0.001$. Hal ini menunjukkan menunjukkan signifikansi data yang dikumpulkan dan diuji, artinya pola konsumsi makanan laut berpengaruh terhadap angka kejadian hipertensi di Kelurahan Malalayang Dua.

Asam lemak $\omega-3$ dan $\omega-6$ dapat ditemukan di makanan laut dan minyak sayur dan disarankan untuk pencegahan penyakit kardiovaskular, dikarenakan asam lemak $\omega-3$ dan $\omega-6$ mengurangi total kolesterol dan TD. ${ }^{10}$ Mekanisme 
bagaimana $\omega$-3 PFA dapat mempengaruhi TD, berdasarkan eksperimen pada binatang adalah: $\omega$-3 PFA menambah kemampuan vasodilator dari endotel, mengurangi reaktifitas tahanan vaskular otot polos pembuluh darah, dan meningkatkan komplians vaskular. ${ }^{11}$

\section{SIMPULAN}

Berdasarkan hasil penelitian dan pembahasan dari penelitian mengenai pengaruh konsumsi makanan laut terhadap kejadian hipertensi di kelurahan Malalayang Dua, maka dapat disimpulkan bahwa angka kejadian hipertensi di masyarakat Malalayang Dua adalah 6,3 \%, komoditi makanan laut yang paling sering dikonsumsi adalah ikan, terlebih khusus ikan cakalang (Katsuwonus pelamis), dan terdapat hubungan yang cukup signifikan $(p=0.001)$ antara konsumsi makanan laut dan menurunnya kejadian hipertensi di Malalayang Dua. Hal ini berpengaruh terhadap angka hipertensi di daerah ini yaitu, $6.3 \%$.

Sehubungan dengan hal ini, perlu bagi masyarakat untuk mengonsumsi makanan laut, terlebih khusus ikan, karena banyak mengandung $\omega-3$ dan $\omega-6$ yang dapat menurunkan tekanan darah dan berbagai risiko kardiovaskular. Untuk penelitian selanjutnya, perlu adanya penambahan jumlah sampel yang lebih banyak dan dilakukan pada berbagai tempat lain yang memiliki perbedaan lingkungan dan pola konsumsi makanan laut untuk melihat variabilitas pola konsumsi makanan laut beserta tekanan darahnya, dan agar hasil yang didapatkan sehubungan dengan konsumsi makanan laut dengan hipertensi dapat lebih akurat.

\section{UCAPAN TERIMA KASIH}

Terima kasih diucapkan kepada penguji 1, dr. Stella Palar, Sp.PD-KGH, penguji 2, Prof. dr. Linda W. A. Rotty, Sp.PD-KHOM, penguji 3, dr. Eko Surachmanto, Sp.PD-KAI dan kepada semua pihak baik secara langsung maupun tidak langsung telah membubuhkan ide, gagasan pada penulis sehingga penulis dapat menyelesaikan artikel ini.

\section{DAFTAR PUSTAKA}

1. Yogiantoro M. Hipertensi esensial. In: Sudoyo AW, Setiyohadi B, Alwi I, Simadibrata M, Setiati S. Buku ajar ilmu penyakit dalam $\left(^{\text {th }}\right.$ edition). Jakarta: Interna Publishing, 2009; p. 1079.

2. Vasan RS et al. Impact of high-normal BP on the risk of cardiovascular disease. New Engl J Med. 2001; 345:1291-1297.

3. Chobanian AV, Bakris GL, Black HR, Cushman WC, Green LA, Joseph L. Izzo Jr JL, et al. Seventh report of the Joint National Committee on prevention, detection, evaluation, and treatment of high blood pressure: the JNC 7 report.JAMA.2003 [cited 2013 Feb 03];289(19):2560-71. Available from http://jama.amaassn.org/cgi/content/full/289/19/2560

4. Williams B. Guidelines for management of hypertension: report of the fourth working party of the British Hypertension Society, 2004-BHS IV. Journal of Human Hypertension. 2004;18: 140.

5. Wahlqvist ML. What's so healthy about seafood - A GUIDE FOR SEAFOOD MARKETERS. Deakin: Fisheries Research and Development Corporation; 2004;2.

6. Madiyono B, Moeslichan S, Sastroasmoro S, Budiman I, Purwanto SH. Perkiraan besar sampel. In: Sastroasmoro S, Ismail S. Dasar -dasar metodologi penelitian klinis. Ed.4. Jakarta: penerbit Sagung Seto; 2011.

7. Guyton AC. Buku ajar fisiologi kedokteran $\left(11^{\text {th }}\right.$ edition). Jakarta: EGC Medical Publisher, 2006.

8. Collette BB, Cornelia EN. Scombrids of the world. An annotated and illustrated catalogue of tunas, mackerels, bonitos and other related species known to date. FAO species catalogue.1983;2.

9. Appleby PN, Davey GK, Key TJ. Hypertension and blood pressure among meat eaters,fish eaters, vegetarians and vegans in EPIC-Oxford. Public Health Nutrition.2002;5(5):645-54. 
732 Jurnal e-Biomedik (eBM), Volume 1, Nomor 1, Maret 2013, hlm. 726-732

10. Soccol MCH, Oetterer. Seafood as functional food. Brazilian Archives of Biology and Ttechnology.2003;46:443-54.

11. Ueshima $H$, Stamler J, Elliott $P$, Chan $Q$, Brown IJ, Carnethon MR, et al. Food $\Omega$ 3 Fatty Acid Intake of Individuals (Total, Linolenic Acid, Long-Chain) and Their Blood Pressure : INTERMAP Study. Hypertension. 2007;50:313-9. 